\title{
BRCA1 functions as a novel transcriptional cofactor in HIV-1 infection
}

\author{
Irene Guendel', Beatrix W Meltzer ${ }^{1}$, Alan Baer', Seth M Dever ${ }^{2,3}$, Kristoffer Valerie ${ }^{2}$, Jia Guo ${ }^{1}$, Yuntao Wu \\ and Kylene Kehn-Hall ${ }^{1 *}$
}

\begin{abstract}
Background: Viruses have naturally evolved elegant strategies to manipulate the host's cellular machinery, including ways to hijack cellular DNA repair proteins to aid in their own replication. Retroviruses induce DNA damage through integration of their genome into host DNA. DNA damage signaling proteins including ATR, ATM and BRCA1 contribute to multiple steps in the HIV-1 life cycle, including integration and Vpr-induced $\mathrm{G}_{2} / \mathrm{M}$ arrest. However, there have been no studies to date regarding the role of BRCA1 in HIV-1 transcription.

Methods: Here we performed various transcriptional analyses to assess the role of BRCA1 in HIV-1 transcription by overexpression, selective depletion, and treatment with small molecule inhibitors. We examined association of Tat and BRCA1 through in vitro binding assays, as well as BRCA1-LTR association by chromatin immunoprecipitation.

Results: BRCA1 was found to be important for viral transcription as cells that lack BRCA1 displayed severely reduced HIV-1 Tat-dependent transcription, and gain or loss-of-function studies resulted in enhanced or decreased transcription. Moreover, Tat was detected in complex with BRCA1 aa504-802. Small molecule inhibition of BRCA1 phosphorylation effector kinases, ATR and ATM, decreased Tat-dependent transcription, whereas a Chk2 inhibitor showed no effect. Furthermore, BRCA1 was found at the viral promoter and treatment with curcumin and ATM inhibitors decreased BRCA1 LTR occupancy. Importantly, these findings were validated in a highly relevant model of HIV infection and are indicative of BRCA1 phosphorylation affecting Tat-dependent transcription.

Conclusions: BRCA1 presence at the HIV-1 promoter highlights a novel function of the multifaceted protein in HIV-1 infection. The BRCA1 pathway or enzymes that phosphorylate BRCA1 could potentially be used as complementary host-based treatment for combined antiretroviral therapy, as there are multiple potent ATM inhibitors in development as chemotherapeutics.
\end{abstract}

Keywords: Antiviral, Small molecule inhibitor, Viral transcription, BRCA1, HIV-1, ATM, Phosphorylation, Post-translational modification

\section{Background}

Human immunodeficiency virus type 1 (HIV-1) is the etiological agent of the acquired immunodeficiency syndrome (AIDS). Currently approved combined antiretroviral therapy (cART) rely primarily on viral-based inhibitors, and present research efforts focus on finding new non-essential host targets that can provide viral inhibition without creating drug-resistance selective pressure on the virus. Therefore understanding the

\footnotetext{
* Correspondence: kkehnhal@gmu.edu

${ }^{1}$ National Center for Biodefense \& Infectious Diseases, School of Systems Biology, George Mason University, Biomedical Research Lab, 10650 Pyramid Place, MS 1J5, Manassas, VA 20110, USA

Full list of author information is available at the end of the article
}

involvement of host factors might present a way to design better approaches to complement treatment and expand therapy considerations for multiple co-infections or HIVassociated malignancies.

The HIV-1 transactivator of transcription, Tat, is an essential regulatory protein that modulates the viral chromatin landscape and transcriptional activation by association with the transactivation response RNA loop region, TAR, present on the proviral $5^{\prime}$ region at the transcriptional initiation site (nt +1 to +57 ) on the HIV1 long terminal repeat (LTR). The Tat/TAR complex is able to recruit various critical host factors including basal transcription factors TBP, TFIIB, TFIID, TFIIH, 
TAF55, and Sp1 [1]. Of importance, Tat/TAR recruits the pTEF-b complex (Cdk9/Cyclin T1) to the RNA polymerase II holoenzyme (RNAP II) that occupies the LTR [2-7]. pTEF-b is a ubiquitous positive acting elongation factor that actively phosphorylates the carboxyl-terminal domain (CTD) of RNAP II, and has been shown to be a critical cofactor for Tat activation of elongation [8-10].

Retroviruses induce DNA damage through integration of their genome into the host DNA. DNA damage signaling proteins including ATR, ATM and BRCA1, contribute to multiple steps in the HIV-1 life cycle, including integration and Vpr-induced G2/M arrest [11-14]. However, there have been no studies to date regarding the role of BRCA1 in HIV-1 transcription. Largely characterized in cancer, the breast cancer susceptibility gene, BRCA1, is a tumor suppressor protein that has implications in processes such as cell cycle, DNA repair, and transcription. These functions are accomplished by BRCA1 interacting with cellular transcription and host factors, in addition to stern regulatory mechanisms $[15,16]$. BRCA1 was first implicated in transcription when its C-terminus [amino acid (aa) 1560-1863] fused to Gal4 was able to activate transcription [17], with aa1760-1863 being the minimal transactivation domain (TAD). Within this TAD are two BRCA1 C-terminus (BRCT) motifs that are found in a large family of proteins important for DNA damage response, such as DNA ligase IV, p53BP1, and base excision response scaffold protein XRCC1 [18]. Since then, numerous other findings have served to strengthen the connection between transcription and BRCA1. For example, BRCA1 is part of the RNAP II holoenzyme complex [19-21]. BRCA1 also interacts with multiple cofactors and transcription factors including CBP/p300, Sp1, STAT1, estrogen receptor and BRG1 [22,23]. Among the genes found to be transactivated by BRCA1 are Mdm2, Bax, p21/Waf1, p27/Kip1, and GADD45a [24-30]. Moreover, BRCA1 has been shown to be in complex with pTEF-b, and Cyclin $\mathrm{T} 1$ has been shown to be an essential factor for BRCA1-dependent activation of RNAP II transcription [31]. Additionally, BRCA1 was reported to interact with the SWI/SNF catalytic core unit BRG1 [32]. In recent years, it has been further linked to chromatin alterations in cancer, including recruitment to sites of DNA repair, indicating a direct function of BRCA1 in transcriptional control through chromatin structure modulation [33-36].

Taking into account these findings and its welldocumented involvement in transcriptional regulation and chromatin remodeling capabilities, we were interested in determining whether BRCA1 participates in HIV-1 Tatdependent transcription. Here, we have demonstrated BRCA1 enhancement of HIV-1 Tat-dependent transcription through gain-of-function and loss-of-function studies. Tat was detected in complex with BRCA1 at aa504-802 through in vitro binding assays and co- immunoprecipitated with BRCA1. Additionally, inhibition of the effector kinase ATM, but not Chk2, resulted in transcriptional decrease by loss of BRCA1 from the viral promoter. Therefore, targeting the host BRCA1 activation pathway can serve as an attractive strategy for the development of novel host-based therapeutics that target HIV-1 viral transcription.

\section{Results and discussion}

\section{BRCA1 enhances HIV-1 Tat-dependent transcription}

The molecular function of BRCA1 has been the subject of intensive studies since it was cloned in 1994 [37]. Primarily in cancer, it has been characterized as a multifaceted tumor suppressor protein due to its role in cell cycle progression, DNA repair and DNA damage response processes, transcription, RNAi pathway regulation, and apoptosis [23,38]. Limited studies have linked BRCA1 to HIV-1. Initially, Zimmerman et al. [13] showed BRCA1-H2AX foci formation was required for Vpr-induced $G_{2}$ arrest. Later, this same group further elaborated on the role of BRCA1 in infection by showing Vpr-induced ATR-dependent activation of BRCA1 at serine substrate S1423 as a response to genotoxic stress, suggesting a model for $\mathrm{Vpr}$-induced apoptosis via transcriptional regulation of the BRCA1 target gene, GADD $45 \alpha$ [11]. Around the same time, Coberley et al. [12] demonstrated alterations of various genes contributing to cell cycle transition at the $G_{2} / M$ checkpoint through a temporal genetic network study in mock or R5-tropic HIV-1 infected primary macrophages. Specifically, infection activated mediators of cell cycling at different times during infection including BRCA1 (intermediate), and GADD $45 \alpha$ (late). Furthermore, BRCA1 may function as a transcriptional coactivator or corepressor, a function that varies depending on its ability to recruit both the basal transcription machinery and proteins implicated in chromatin remodeling [32,39]. Consequently, we were interested in characterizing BRCA1 function in HIV-1 transcription.

First we started our functional transcription studies in cells that have a null background for BRCA1 expression. UWB1.289 cells are derived from ovarian cancer in a germ line BRCA1 mutation carrier and lack expression of BRCA1, while UWB1.289 + BRCA1 cells are a stable UWB1.289 derivative cell line carrying a pcDNA3 plasmid coding for wild-type BRCA1 [40]. Here we cotransfected both set of cells with HIV-1 LTR-Luc, pcDNA or Tat, and Renilla reporter plasmid as a control for transfection efficiency between cell lines. Based on scored luciferase activity, results in Figure 1A indicate that there is $\sim 13$-fold difference in Tat transactivation of the HIV-1 LTR in cells expressing BRCA1 (lane 2, black bar) when compared to the BRCA1 null cells (lane 2, white bar). Next, we were interested in assessing the 
A)

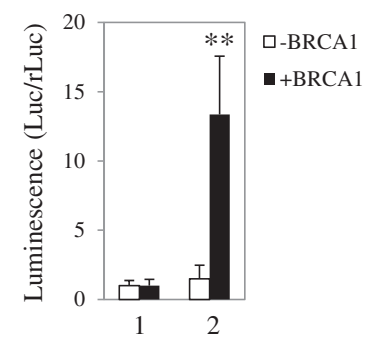

HIV-1 LTR + +

Renilla reporter ++
B)

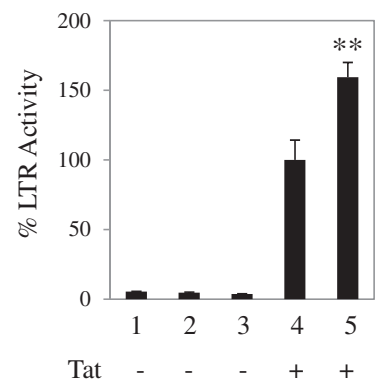

pcDNA - + - + -
C)

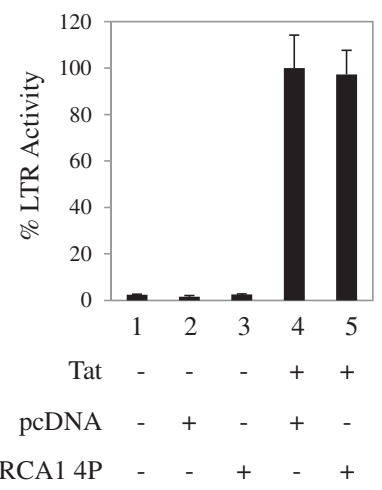

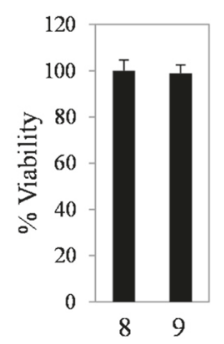

D)
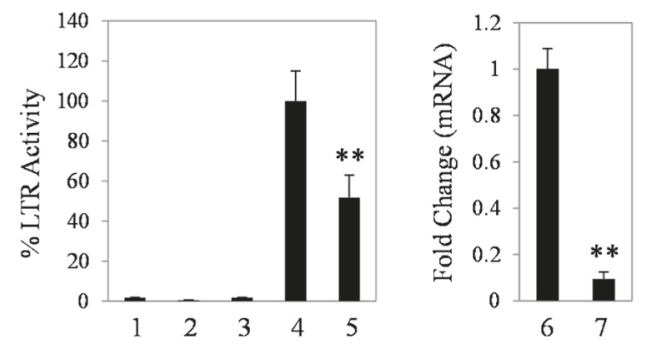

siGFP + siGFP siGFP siBRCA1 siBRCA1 siBRCA1

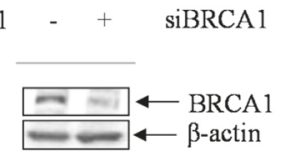

Figure 1 HIV-1 Tat-dependent transcription is more efficient in cells containing BRCA1. A. UWB1.289 BRCA1 null and UWB1.289+ BRCA1 cells and were co-transfected with pcDNA or pcTat, LTR-Luc, and CMV-Luc (Renilla) plasmid DNA. Dual-Glo luciferase assay was performed 48 hours later as described by the manufacturer. Raw data was normalized to Renilla luciferase expression in both cell lines, fold changes were calculated against pcDNA (-Tat) condition for each cell line. B. TZM-bl cells were co-transfected with pcDNA or pcTat, and BRCA1 (wild-type) plasmid DNA. Bright-Glo luciferase assay was performed 48 hours pos-transfection as described by the manufacturer. Cells containing pcTat and pcDNA were used as baseline value for Tat-dependent LTR activation. C. TZM-bl cells were co-transfected with pcDNA or pcTat, and BRCA1 4P (mutant) plasmid DNA (S1387A, S1423A, S1457A, and S1524A). Bright-Glo luciferase assay was performed 48 hours post-transfection. Cells containing pcTat and pcDNA were used as baseline value for Tat-dependent LTR activation. D. TZM-bl cells were co-transfected with pcTat or siRNA against GFP (control) and BRCA1. Bright-Glo luciferase assay was performed 48 hours post-transfection (left panel). Cells containing pcTat and siGFP were used as baseline value for Tat-dependent LTR activation. BRCA1 depletion was confirmed by qRT-PCR and western blot (middle panel and inset). Fold changes against siGFP were calculated relative to Actin using the $\Delta \Delta \mathrm{Ct}$ method. CellTiter-Glo cell viability assay (right panel) was performed as described by the manufacturer and viability normalized to cells transfected with siGFP. Transfection assays were performed in triplicate and data plotted represents averaged data of two independent experiments. Error bars show the standard error of two averaged independent measurements. Viability assays were performed in triplicate. Western blots were performed for two independent experiments. Double asterisk indicates statistically significant difference $p \leq 0.01$. 
effect of BRCA1 overexpression in the context of integrated proviral DNA. To this end, we co-transfected pcDNA or Tat, and BRCA1 into TZM-bl cells followed by measurement of the HIV-1 LTR activity through luciferase assays. The TZM-bl cell line is a widely used reporter system for the study of Tat-dependent transcription as it harbors the luciferase gene under the control of an integrated HIV-1 5' LTR. Results in Figure 1B show a significant transcriptional enhancement ( $60 \%$ increase) when BRCA1 is overexpressed in comparison to pcDNAtransfected cells (compare lanes 5 and 4). Importantly, we did not observe any effects of BRCA1 overexpression in the absence of Tat, suggesting a Tat-dependent effect (lanes 2 and 3). Given that BRCA1 is activated by phosphorylation [23], which has also been noted to occur during HIV-1 infection [11], we assessed the importance of BRCA1 phosphorylation in the enhancement of HIV-1 transcription. To this end, we utilized a BRCA1 mutant construct with amino acid substitutions for the ATR/ ATM target serine residues S1387A, S1423A, S1457A, and S1524A (BRCA1 4P). Similarly, TZM-bl cells were co-transfected with Tat or pcDNA, and BRCA1 4P for 48 hours, with subsequent Tat-dependent HIV-1 LTRdriven luciferase expression quantification. Results in Figure $1 \mathrm{C}$ showed no transcriptional enhancement between cells containing control DNA or BRCA1 4P (lanes 4 and 5), indicating that BRCA1 activation by phosphorylation is important for the enhancement of Tat dependent LTR transcription. Likewise, we did not see any effects of BRCA1 4P overexpression in our basal controls (lanes 2 and 3).

Based on these findings, we next wanted to examine the functional consequences of BRCA1 selective depletion in Tat-dependent transcription. To assess the effect of BRCA1 knockdown in HIV-1 transcription, we first screened various siRNAs against BRCA1 and selected the one producing more effective depletion results (data not shown). TZM-bl cells were co-transfected with Tat and siRNA against BRCA1 or GFP as a non-specific control, and luciferase assays were performed 48 hours post-transfection. Results in Figure 1D show that luciferase activity was significantly reduced by $\sim 49 \%$ in cells transfected with siBRCA1 compared to cells transfected with siGFP (compare lanes 4 and 5). As additional controls, BRCA1 levels in these cells were assayed by qRTPCR and western blot. BRCA1 was successfully repressed $(\sim 90 \%)$ at the transcriptional level (compare lanes 6 and 7) and protein levels were decreased by $\sim 68 \%$ (inset western blot panel). To discard the possibility that the decrease in Tat-dependent transcription was due to cytotoxic effects upon BRCA1 knockdown, we performed viability assays on these samples. No changes in cell viability were observed between samples transfected with control siRNA or BRCA1 siRNA (compare lanes 8 and 9), indicating that the transcriptional efficiency loss is specific to BRCA1 selective depletion. Collectively, these data support the permissive role of BRCA1 for Tat-dependent HIV-1 transcription.

\section{BRCA1 is in complex with Tat}

Collectively, molecular studies have shown $\sim 1,500$ interactions between HIV-1 and human host proteins [41]. In terms of Tat, the most studied interaction is its association with the pTEF-b Cyclin T1 subunit by which it exerts Tat-dependent transcriptional activation of the HIV-1 promoter [1]. Because of the fact that Tat is known to be in complex with various transcription factors and host transcriptional machinery, we were interested in determining whether these proteins associate. To this end, GST-BRCA1 constructs spanning the full length of the protein (Figure 2A) and GST-Tat were utilized in a pull-down assay from Flag-Tat transfected TZM-bl whole cell lysates. TZM-bl cells were chosen as they express robust levels of BRCA1 (see Figure 1D), and are our base cell line for our transcriptional assays. Beads bound to GST protein (lane 2, panel B) were used as a background control. Membranes were probed with antibodies against Flag (top panel) and BRCA1 (bottom panel). Western blot results in Figure 2B indicate that the only detectable association between the GST-BRCA1 fragments and Flag-Tat occurs at the aa504-802 region (lane 4, top panel), while GST-Tat inversely confirmed the BRCA1-Tat association observed with full length endogenous BRCA1 present in the TZM-bl lysate (lane 8, bottom panel). In addition, we saw GST-Tat binding to the Flag-Tat present in the cell lysate (lane 8 , top panel), doubling as a positive binding control given that Tat exists as a $\mathrm{Zn}^{2+}$ - or $\mathrm{Cd}^{2+}$-linked dimer [42]. To further corroborate this interaction, whole cell extracts from Tat-transfected TZM-bl cells were immunoprecipitated with BRCA1 or IgG and western blotted with anti-BRCA1, Flag, and BRG1 antibodies. Results in Figure $2 \mathrm{C}$ show that BRCA1-Tat interaction was observed specifically with the BRCA1 immunoprecipitation and not with the IgG. Probing against BRG1 was used as an immunoprecipitation control since it has been shown to be a BRCA1-binding partner [32]. Collectively, these results indicate that physical interaction of BRCA1-Tat is detectable at the aa504-802 region of BRCA1, suggesting that these proteins are associated and accordingly, supporting BRCA1 participation in Tat-dependent transcription.

\section{BRCA1 status affects enhancement of Tat-dependent transcription during infection with pseudotyped particles} To further discern the role of BRCA1 in Tat-dependent transcription, we generated pseudotyped HIV-1 LTRdriven reporter viral particles. Figure $3 \mathrm{~A}$ shows the 
A)

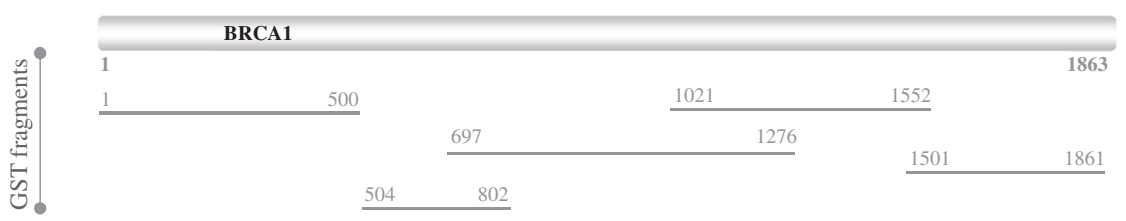

B)

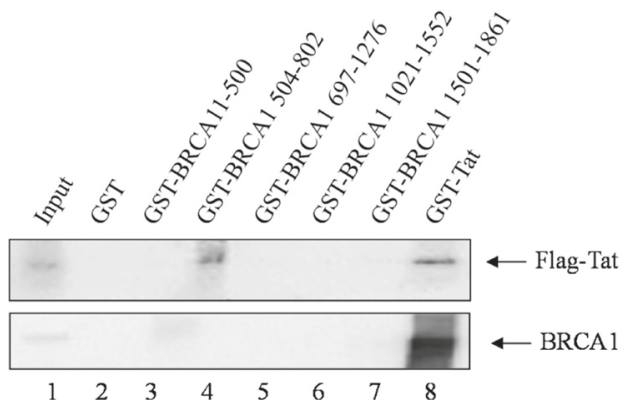

C)

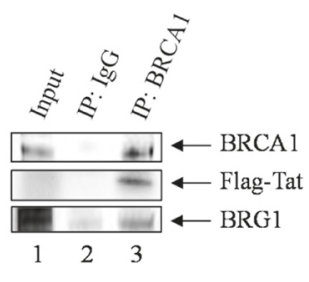

Figure 2 BRCA1 associates with Tat. A. Schematic of five GST-BRCA1 fragments spanning the whole length protein. B. TZM-bl cells were transfected with Flag-Tat plasmid DNA for 48 hours. One milligram of whole cell protein extract was incubated with $1 \mu \mathrm{g}$ GST-BRCA1 constructs overnight and processed as described in the Methods section. Samples were analyzed by western blot (top panel WB: anti-Flag, bottom panel WB: anti-BRCA1). C. TZM-bl cells were transfected with Flag-Tat plasmid DNA for 48 hours. One milligram of TZM-bl whole cell protein extract was immunoprecipitated with antiBRCA1 and anti-lgG antibodies and analyzed by western blot (top panel WB: anti-BRCA1, middle panel WB: anti-Flag, bottom panel WB: anti-BRG1). Western blots are representative of two independent experiments.

general structure of the LTR-driven reporter plasmid pNL-RRE-SA-Luc that was used to incorporate the luciferase reporter gene. To assay the impact of BRCA1 status in Tat-dependent transcription in a live infection, we utilized the UWB1.289 and UWB1.289+BRCA1 cells for their unique ability to provide clean contrasts of BRCA1 expression. Cells were co-transfected with pcTat and Renilla reporter 24 hours prior to infection. Next, cells were infected and processed for luciferase assays 24 hours post-infection to allow for sufficient proviral integration and transcription to take place. Results in Figure 3B indicate that in vNL-Luc infected cells, LTR activation was observed at a lower level in BRCA1 cells (lane 2, white bar) when compared to + BRCA1 cells (lane2, black bar), which exhibited a 8fold increase in LTR activity over its -BRCA1 counterpart. No significant background activation was detected in + Tat mock infected cells (lane 1). Collectively, these findings support our initial assays performed in these cells with a non-integrated HIV-LTR reporter plasmid (Figure 1A), where we detected a more tolerant environment for Tat-dependent transcription to occur in the presence of BRCA1. Moreover, these results provide further support that the enhancement of transcription by BRCA1 is Tat-dependent.

Given the importance of BRCA1 to the cell cycle and the fact that HIV-1 transcription has been shown to be enhanced in the G2 phase of the cell cycle [11-13,23,43,44], experiments were performed to determine if UWB1.289 cells had a difference in cell cycle distribution. It has been previously shown that UWB1.289 cells display no difference in cell cycle profile in the absence of stress, but when cells were subjected to irradiation, a G2/M arrest was observed with the BRCA1 complemented cells [40]. To determine if any alterations in cell cycle were occurring in the UWB1.289 and UWB1.289 + BRCA1 cells following HIV infection, cell cycle analysis using propidium iodine staining and flow cytometry was performed. No changes in cell cycle distribution between these two cell derivatives were observed (Figure 3C). As Sp1 is a well-known interacting partner of BRCA1, the binding of Sp1 to the LTR in the presence and absence of BRCA1 was assessed by chromatin immunoprecipitation. ChIP assays from vNL-Luc infected -BRCA1 and + BRCA1 cells were performed using antibodies against RNAP II (positive control), V5 (negative control) and Sp1. There was no significant difference in Sp1 or RNAP II binding to the LTR between the two cell populations (Figure 3D), indicating that differential binding of Sp1 to the LTR is not a contributing factor to the decreased LTR activation observed in the -BRCA1 cells. Collectively, these results suggest that BRCA1 plays a direct and critical role in Tat-dependent HIV transcription independent of cell cycle effects.

\section{Small molecule inhibition of BRCA1 gene expression affects HIV-1 Tat-dependent transcription}

Currently, there are no therapeutic agents specifically targeting BRCA1. However recently, it has been documented 
A)

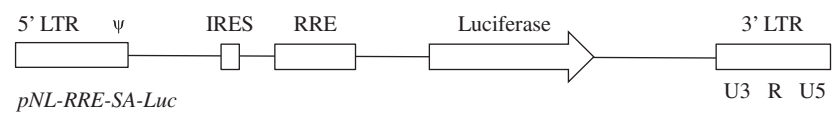

B)

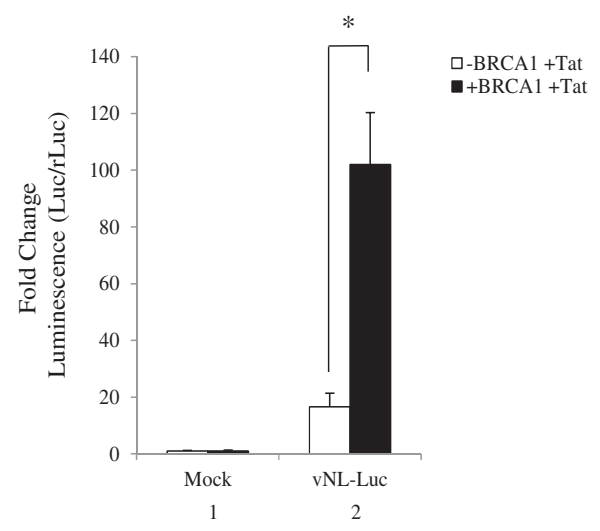

C)

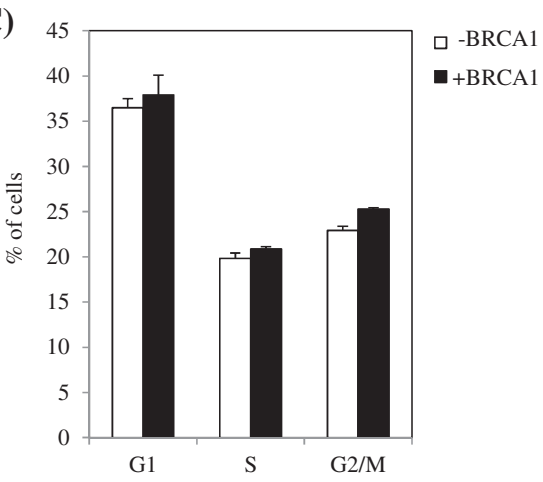

D)

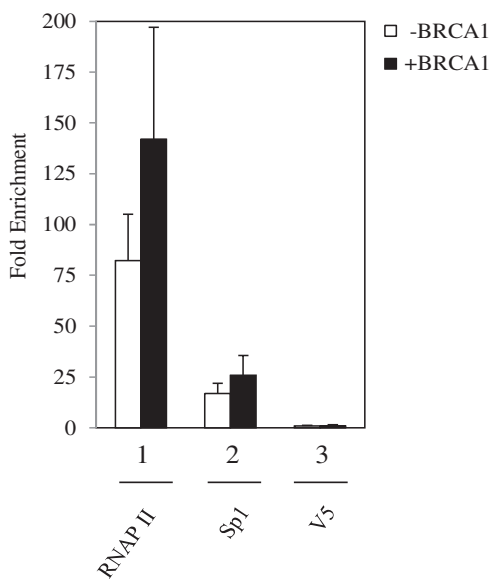

Figure 3 BRCA1 status affects enhancement of Tat-dependent transcription during infection with pseudotyped particles. A. Schematic depicting the LTR-driven reporter plasmid pNL-RRE-SA-LUC. B. UWB1.289 BRCA1 null and UWB1.289+ BRCA1 cells and were co-transfected with pcTat and CMV-Luc (Renilla) plasmid DNA 24 hours prior to infection with LTR-driven reporter viral particles. Dual-Glo luciferase assay was performed 24 hours post-infection as described by the manufacturer. Raw data was normalized to Renilla luciferase expression in both cell lines, fold changes were calculated against + Tat mock infected cells (lane 1). Transfection and infection assays were performed in triplicate and data plotted represents averaged data of two independent experiments. Single asterisk indicates $p<0.05$. C. UWB1.289 BRCA1 null and UWB1.289 + BRCA1 cells were infected with VSVG-pseudotyped NL4-3. Cells were collected 48 hours post-infection, stained with propidium iodine, and analyzed by flow cytometry. Results are representative of three biological replicates. D. Cells were infected as described above and collected at 48 hours post-infection for ChIP analysis. Antibodies used for ChIP were anti-RNA polymerase II (RNAP II, $10 \mu \mathrm{g})$, anti-Sp1 (10 $\mu \mathrm{g})$, and anti-V5 $(10 \mu \mathrm{g})$. Quantitative PCR was performed using SYBR Green PCR Master Mix to analyze immunoprecipitated material.

that curcumin reduces expression of the BRCA1 gene by histone acetylation impairment at the BRCA1 promoter [45]. Generally, curcumin is categorized as a multifactorial compound characterized by tolerable doses linked to antioxidant therapy, anti-tumor effects, and anti-viral effects [45-50]. Moreover, curcumin has been shown to suppress pathways concomitant to HIV-1 replication and HIV-1 associated neurocognitive disorders (HAND); and when administered as adjuvant therapy to existing cART, curcumin has been shown to enhance the protease inhibitor indinavir antiretroviral activity in persistently infected cells [51-54]. In addition, a recent study demonstrated multi-pathway involvement in curcumin-induced inhibition of Tat-dependent transcription [55]. Here, the authors showed modulation of the HDAC1/NF- $\mathrm{kB}$ pathway used by HIV-1 to exert chromatin remodeling at the viral promoter and further promoter activation by NF-kB. Despite curcumin not being BRCA1-specific, we were interested in using the compound as a model for small molecule inhibition of BRCA1. 
To confirm previously published findings in our cellbased system, TZM-bl cells were treated for 24 hours with vehicle (DMSO) or a titration of curcumin determined from concentrations used in the literature $(0.5,1$, 10 , and $20 \mu \mathrm{M})$. Western blot was then performed using anti-BRCA1 and anti- $\beta$-actin antibodies to determine the expression levels of BRCA1. Results in Figure 4A show a dose-dependent loss of BRCA1 expression with curcumin treatment when compared to DMSO (compare lanes
1 to $2-5)$. Next, we confirmed Tat-dependent transcription inhibition by treating Tat-transfected TZM-bl cells with $20 \mu \mathrm{M}$ of curcumin. Results in Figure 4B show a significant decrease in transcription ( 46\%) with curcumin when compared to DMSO (compare lanes 3 and 4) that is specific to treatment and not due to compound cytotoxicity (compare lanes 5 and 6) and likens previously published data [55]. We next sought to determine if BRCA1 was present at the HIV-1 LTR, and if curcumin treatment

A)

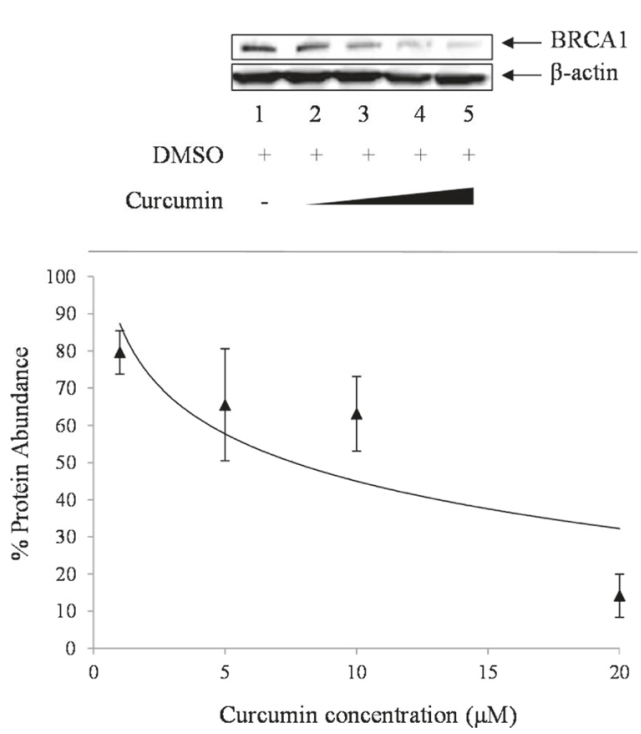

B)

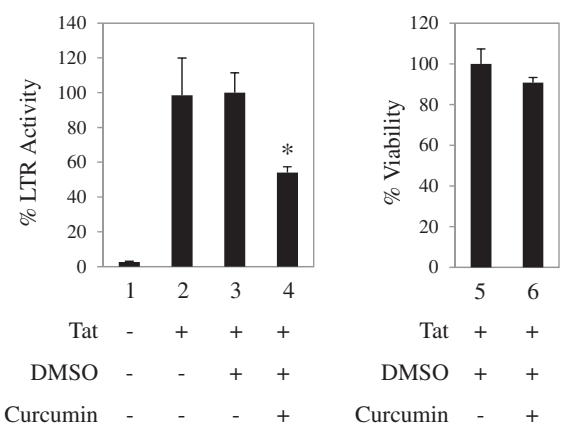

C)

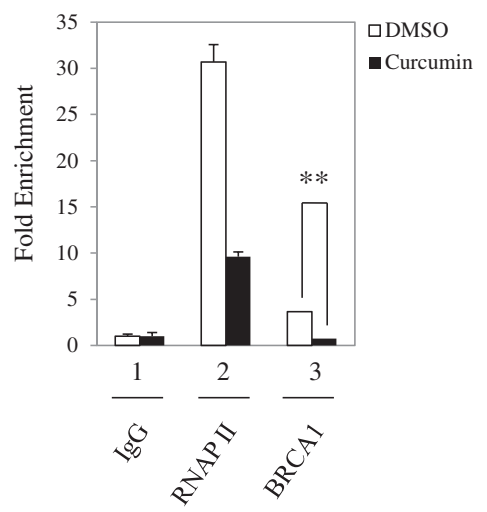

Figure 4 Curcumin decreases BRCA1 occupancy at the HIV-1 LTR. A. TZM-bl cells were transfected with pcTat and treated the next day with vehicle (DMSO) or a titration of curcumin $(0.5,1,10$, and $20 \mu \mathrm{M})$. Samples were analyzed by western blot. Inset depicts a dose-response curve of BRCA1 protein abundance versus curcumin treatment based on the average densitometry counts with error bars representing standard error of three independent measurements. Western blot is representative of three independent experiments. Densitometry counts were taken from three independent treatments to acquire a dose-response curve of BRCA1 expression inhibition (inset plot) B. TZM-bl cells were transfected with pcTat and treated the next day with DMSO or $20 \mu \mathrm{M}$ curcumin. Bright-Glo luciferase assays and CellTiter-Glo cell viability assays were performed 24 hours posttreatment as described by the manufacturer. Data was normalized to cells containing Tat and treated with DMSO as baseline for Tat-dependent LTR activation. Transfection and treatment assays were performed in triplicate and data plotted represents averaged data of two independent experiments. Error bars show the standard error of two averaged independent measurements. Viability assays were performed in triplicate. C. TZM-bl cells were transfected with pcTat and treated the next day with DMSO or curcumin $(20 \mu \mathrm{M})$ for 24 hours prior to being collected for ChIP analysis. Antibodies used for ChIP were anti-BRCA1 $(10 \mu \mathrm{g})$, anti-lgG $(10 \mu \mathrm{g})$, and anti-RNA polymerase II (RNAP II, $10 \mu \mathrm{g})$. Quantitative PCR was performed using SYBR Green PCR Master Mix to analyze immunoprecipitated material. Single asterisk indicates $p<0.05$ and double asterisk indicates statistically significant difference $p \leq 0.01$. 
could modulate its binding. ChIP assays from Tattransfected DMSO- or curcumin-treated $(20 \mu \mathrm{M})$ TZM-bl cells were performed using antibodies against RNAP II (positive control), IgG (negative control) and BRCA1. Interestingly, we observed the presence of BRCA1 at the viral promoter (Figure 4C). To our best knowledge, this is the first instance that BRCA1 has been detected at the HIV-1 LTR. Conversely curcumin treatment resulted in a significant $\sim 2.9$-fold loss of BRCA1 occupancy from the activated HIV-1 LTR when compared to the DMSO control (lane 3). Collectively, these results are suggestive of BRCA1 playing a role in HIV-1 Tat dependent transcription, and implies the use of chemotherapeutic agents treating BRCA1 as a druggable target.

\section{Inhibition of upstream BRCA1 phosphorylation effectors, ATR/ATM, decreases Tat-dependent transcription}

BRCA1 contains a serine cluster domain (SCD) spanning aa1280-1524, a common motif present in ATR/ATM protein targets [56]. ATR phosphorylates BRCA1 on serine 1423 in response to UV damage or HU-induced replication arrest [57], while ATM-mediated phosphorylation events at serines 1387, 1423, 1457 and 1524, have been characterized in response to ionizing radiation-induced damage [58,59]. While the Chk2 phosphorylation site is not located within the SCD region, its phosphorylation of serine 988 occurs in response to the same stressors as with ATM [60]. Because cellular stress was shown to be highly conducive to HIV-1 replication [61], we next looked at the effect of ATR/ATM inhibition on Tat-dependent HIV-1 transcription. TZM-bl cells were transfected with Tat and treated the next day with vehicle or a titration of caffeine. Caffeine is a methylxanthine that has been used extensively to study ATR/ATM signaling as a natural inhibitor of these kinases [62]. Forty eight hours post-treatment the cells were subjected to luciferase assays. As can be observed in Figure 5A, there is a dose-dependent decrease in HIV-1 transcription with increasing concentrations of caffeine of up to $\sim 88 \%$ inhibition when compared to vehicle (compare lane 2 to 3-5). To confirm compound inhibition specificity, we performed cell viability assays of treated cells to measure inhibitor-induced cell death. Results in Figure 5B show that caffeine was not toxic at $500 \mu \mathrm{M}$ or $2 \mathrm{mM}$. Working concentrations in published literature use caffeine up to $10 \mathrm{mM}$, however we observed that in our system, $5 \mathrm{mM}$ caffeine decreased cell viability by $\sim 60 \%$ (lane 5). Thus, treatment with $2 \mathrm{mM}$ caffeine results in a viable $\sim 60 \%$ Tat-dependent transcriptional activity decrease without exhibiting cytotoxicity.

Given that caffeine is a generic inhibitor, we wanted to explore treatment with a more specific compound. To confirm the importance of ATM in this process, the small molecule ATM inhibitor, KU55933 (which we will refer to henceforth as ATMin) was utilized. This inhibitor has been shown to specifically inhibit ATM in the low $\mathrm{IC}_{50}$ of $12.9 \mathrm{nM}$ without inhibiting ATR at doses of up to $100 \mu \mathrm{M}$ [63]. As Chk2 also phosphorylates BRCA1 in response to DNA damage [64], a Chk2 inhibitor (Chk2in) was also tested. TZM-bl cells were transfected with Tat and treated the next day with vehicle or a titration of ATMin or Chk2in. Forty eight hours post-treatment the cells were subjected to both luciferase (Figure $5 \mathrm{C}$ ) and viability assays (Figure 5D). The results showed a dose-dependent Tat-dependent LTR transcriptional inhibition of up to $\sim 55 \%$ in the presence of ATMin but not Chk2in (compare lanes 6 and 9, panel C), demonstrating ATM kinase specificity in this inhibitory process. Both inhibitors showed no cytotoxicity. To further confirm the specific participation of ATM in Tat-dependent transcription, we performed ATM selective depletion in Tat-transfected TZM-bl cells. Results in Figure 5E indicate that upon ATM knockdown, Tat transactivation of the viral promoter is decreased by $\sim 45 \%$. As additional controls, ATM levels in these cells were assayed by qRT-PCR and western blot. ATM expression was successfully decreased $(\sim 40 \%)$ at the transcriptional level (compare lanes 3 and 4) and protein levels were decreased by $\sim 54 \%$ (inset panel) as confirmed by western blot using antibodies against ATM and $\beta$-actin as a loading control.

In order to functionally link the inhibitor study findings to BRCA1, ChIP assays from Tat-transfected DMSO- and ATMin-treated TZM-bl cells were performed using antibodies against Histone $\mathrm{H} 3$ phosphorylated at serine 10 [pS10-H3 (positive control)], V5 (negative control), and BRCA1. Results in Figure 5F reveal total BRCA1 (lane 3, compare white and black bars) occupancy loss ( 2-fold) from the activated HIV-1 LTR with ATMin treatment when compared to the DMSO control. It is important to note that we also observed a decrease in pS10-H3 binding to the LTR following ATMin treatment as well as a decrease in RNAP II binding following curcumin treatment (Figure 4C). These results indicate that these treatments are affecting more than just BRCA1 binding to the LTR. As we hypothesize that BRCA1 may be acting as a scaffold protein, there are likely multiple LTR binding factors that will be influenced if BRCA1 leaves the LTR. However, we cannot rule out a global change at the promoter after treatments that is affecting multiple binding partners. Taken together, these results suggest that BRCA1 phosphorylation plays a role in Tat-dependent transcription as observed indirectly by the inhibition of upstream BRCA1 activators. Also, they are suggestive of ATM-dependent BRCA1 phosphorylation requirement for its recruitment to the HIV-1 LTR in the presence of Tat. Moreover, these results show that LTR transcription is potently and specifically inhibited by ATMin. These observations are correlated with various studies implicating these kinases in HIV-1 infection [14,65-68]. For example, caffeine and 


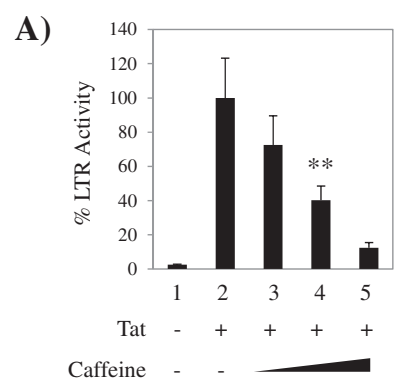

C)

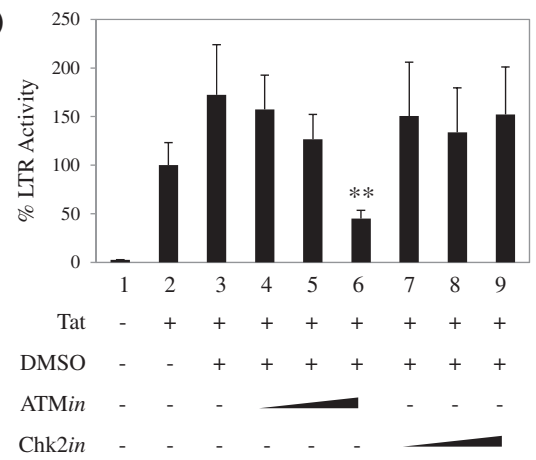

E)

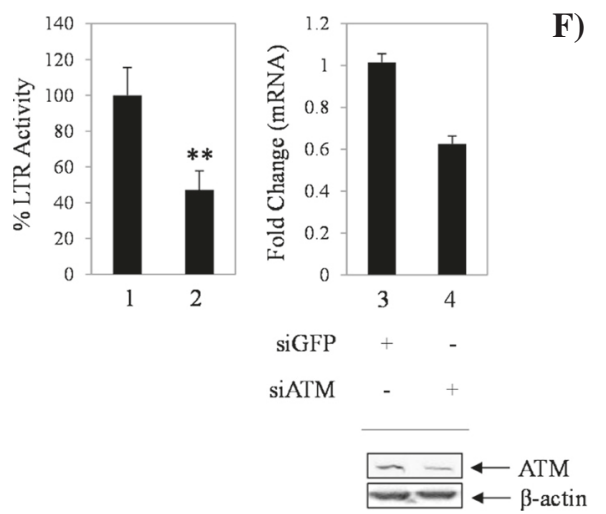

B)

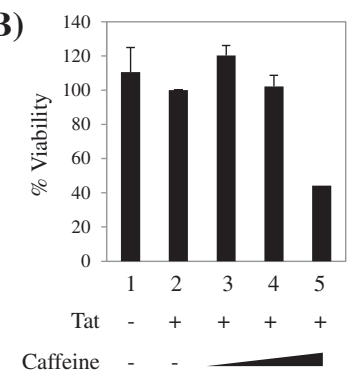

D)

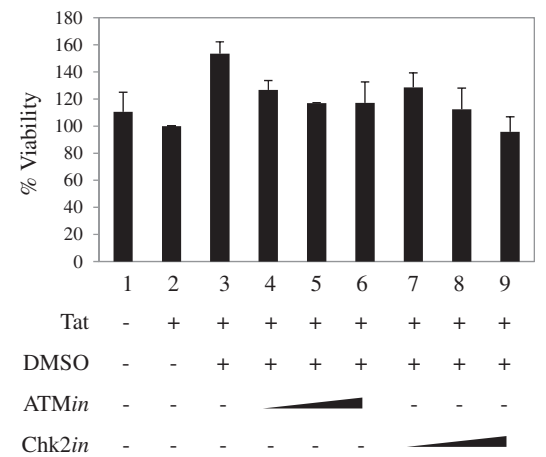

F)

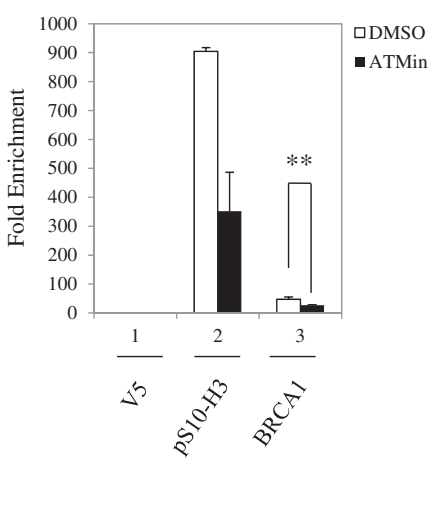

Figure 5 Inhibition of upstream BRCA1 phosphorylation effectors ATR/ATM, decreases Tat-dependent transcription. A. TZM-bl cells were transfected with pcTat and treated the next day with vehicle (water) and a titration of caffeine $(500 \mu \mathrm{M}, 2 \mathrm{mM}$ and $5 \mathrm{mM})$. Bright-Glo luciferase assays were performed 48 hours post-treatment. Data was normalized to cells containing Tat and treated with DMSO as baseline for Tat-dependent LTR activation. B. CellTiter-Glo cell viability assays were performed 48 hours post-treatment. Data was normalized as in panel A. C. TZM-bl cells were transfected with pcTat and treated the next day with vehicle (DMSO) and a titration of ATM or Chk2 inhibitors (ATMin and Chk2in) at $0.1 \mu \mathrm{M}, 1 \mu \mathrm{M}$ and $10 \mu \mathrm{M}$. Bright-Glo luciferase assays were performed 48 hours post-treatment. Data was normalized as in panel A. D. CellTiter-Glo cell viability assays were performed 48 hours post-treatment. Data was normalized as in panel A. E. TZM-bl cells were co-transfected with pcTat or siRNA against GFP (control) and ATM. Bright-Glo luciferase assays were performed 48 hours post-treatment. Cells containing pcTat and siGFP were used as baseline value for Tat-dependent LTR activation. ATM depletion was confirmed by qRT-PCR and western blot (right panel and inset). Fold changes against siGFP were calculated relative to Actin using the $\triangle \triangle \mathrm{Ct}$ method. $\mathbf{F}$. TZM-bl cells were transfected with pcTat and treated the next day with DMSO or ATM inhibitor $(10 \mu \mathrm{M})$ for 48 hours prior to being collected for ChIP analysis. Antibodies used for ChIP were antiBRCA1 $(10 \mu \mathrm{g})$, anti-V5 $(10 \mu \mathrm{g})$, and anti- pS10-H3 $(10 \mu \mathrm{g})$. Transfection and treatment assays were performed in triplicate and data represents averaged data of two independent experiments. Viability assays were performed in triplicate. Error bars show the standard error of two averaged independent measurements. Double asterisk indicates statistically significant difference $p \leq 0.01$.

caffeine-related methylxanthines, including FDA-approved theophylline, have been used to inhibit HIV-1 integration in primary cells [65]. Similarly, HIV-1 IN has been shown to stimulate an ATM-dependent DNA damage response and that in the absence of this enzyme, cells are sensitized to retroviral-induced death [67]. Thus, treatment with ATMin suppressed viral replication, not only of wild-type, but drug-resistant HIV-1. Of interest for the present study, caffeine has been found to prevent pTEF-b dissociation from its 7SK snRNP inactive complex, illustrating an 
additional mechanism for its inhibition of Tat-dependent transcription [69].

\section{BRCA1 is present at the HIV-1 LTR in HIV infected T-cells} Finally we aimed to confirm our findings in a T-cell model of infection. To this end, CEM T-cells were infected with HIV and BRCA1 occupancy of the LTR assessed by chromatin immunoprecipitation. ChIP assays from HIV (NL43) infected CEM T-cells were performed using antibodies against pS10-H3 (positive control), V5 (negative control), and BRCA1. Indeed, we observed BRCA1 present at the LTR in HIV infected T-cells (Figure 6A). Next we examined if inhibition of BRCA1 phosphorylation through the use of the ATMin would alter BRCA1 binding to the LTR. CEM cells were pre-treated with ATMin for 2 hours prior to infection. ATMin was also added following infection. Interestingly, no significant difference in BRCA1 binding to the LTR was observed after ATMin treatment (Figure 6B). However, a decrease in p-BRCA1 (S1423) was observed after ATMin treatment, indicating that there was a shift in the form of BRCA1 bound at the LTR following ATMin treatment. Collectively these results indicate that BRCA1 is present at the HIV-1 LTR in a highly relevant model of HIV infection.

\section{Conclusions}

Our data has shown that BRCA1 functions as an enhancer of HIV-1 transcription through gain-of-function and loss-of-function studies. We have shown that BRCA1 region aa504-802 associates with Tat, encouraging the idea of its participation in Tat-dependent transcription. We have also used small molecule inhibitors as tools to assess the inhibitory effect of its targets on Tat-dependent HIV-1 5' LTR transcription, highlighting the viability of therapeutic approaches targeting host cell proteins. BRCA1 phosphorylation in HIV-1 infected cells has primarily been described as a function of ATR as the effector kinase and as a DNA damage response event [11]. These data explored the effects of ATR/ATM-mediated phosphorylation of BRCA1 in Tat-dependent transcription. More importantly, we have shown for the first time that BRCA1 is present at the HIV-1 LTR in infection and that LTR occupancy by the phosphorylated species is decreased upon treatment with ATMin.

\section{Methods}

\section{Cell culture and reagents}

TZM-bl cells are engineered HeLa cells that express $\mathrm{CD} 4, \mathrm{CCR}_{5}$, and $\mathrm{CXCR}_{4}$ and contain integrated reporter genes for Firefly luciferase and $\beta$-galactosidase under the control of an HIV-1 long terminal repeat [70,71]. These cells were cultured to confluency in DMEM supplemented with $10 \%$ heat-inactivated FBS, 1\% L-glutamine, and $1 \%$ streptomycin/penicillin (Gibco/BRL, Gaithersburg, MD, USA). UWB1.289 cells are derived from ovarian cancer in a germ line BRCA1 mutation carrier and lack expression of BRCA1 [40]. UWB1.289 + BRCA1 cells are a stable UWB1.289 derivative cell line carrying a pcDNA3 plasmid coding for wild-type hemagglutinintagged BRCA1 [72]. Cells were purchased from the
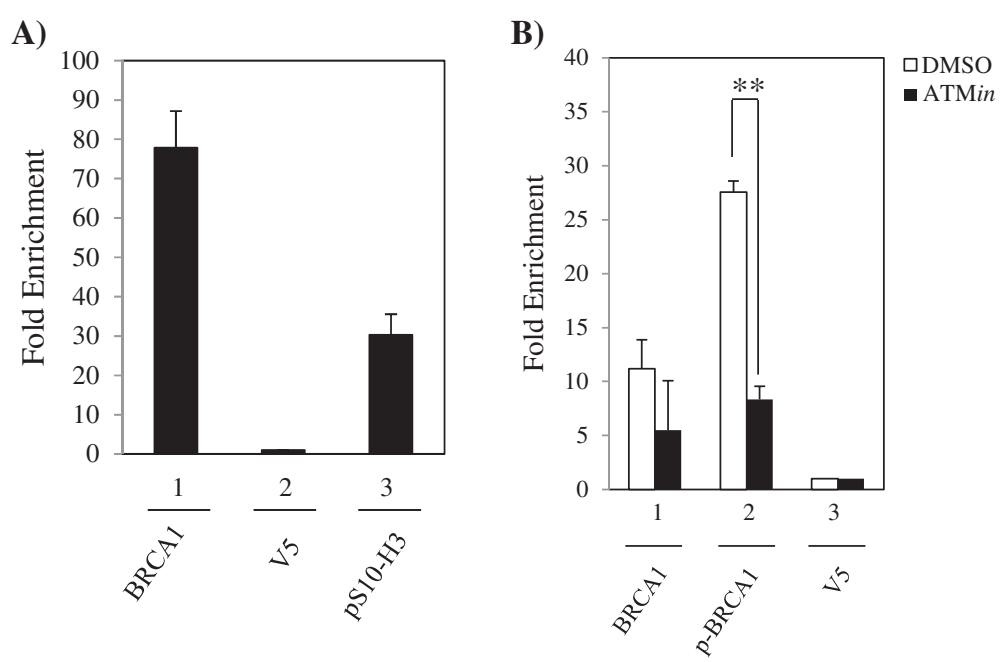

Figure 6 BRCA1 is present at the HIV-1 LTR in HIV infected T-cells. A. CEM cells were infected with NL4-3 virus (p24=5000 pg/ml) for 4 hours and

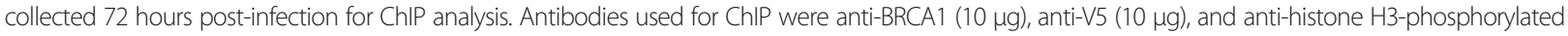
at S10 (pS10-H3, $5 \mu \mathrm{g})$. Quantitative PCR was performed using SYBR Green PCR Master Mix to analyze immunoprecipitated material. B. CEM cells were pre-treated with DMSO or $10 \mu \mathrm{M}$ ATM inhibitor (ATMin) for 2 hours. Cells were then infected with NL4-3 virus (p24=5000 pg/ml) for 4 hours, followed by post-treating the cells with DMSO or ATMin. Cells were collected 72 hours post-infection for ChIP analysis. Antibodies used for ChIP were anti-BRCA1 $(10 \mu \mathrm{g})$, p-BRCA1 S1423 $(10 \mu \mathrm{g})$, and anti-V5 $(10 \mu \mathrm{g})$. Quantitative PCR was performed using SYBR Green PCR Master Mix to analyze immunoprecipitated material. Double asterisk indicates statistically significant difference $p \leq 0.01$. 
American Type Culture Collection (Manassas, VA, USA) and were maintained in 1:1 RPMI 1640/MEGM (Lonza, Walkersville, MD, USA) supplemented with $3 \%$ fetal bovine serum. CEM is an uninfected T-cell line and is grown in RPMI media containing 10\% FBS, 1\% L-glutamine, and 1\% streptomycin/penicillin.

\section{Protein extracts and immunoblotting}

Cells were collected, washed once with PBS and pelleted. For immunoprecipitation, cells were lysed in a buffer containing Tris- $\mathrm{HCl} \mathrm{pH} 7.5,120 \mathrm{mM} \mathrm{NaCl}, 5 \mathrm{mM}$ EDTA, $0.5 \%$ NP-40, $50 \mathrm{mM}$ NaF, $0.2 \mathrm{mM}$ Na3VO4, $1 \mathrm{mM}$ DTT and one tablet complete protease inhibitor cocktail per $50 \mathrm{ml}$. Lysis was performed under ice-cold conditions, incubated on ice for $30 \mathrm{~min}$ and spun at $4^{\circ} \mathrm{C}$ for $5 \mathrm{~min}$ at $14,000 \mathrm{rpm}$. The protein concentration for each preparation was determined with by Bradford assay (Sigma Aldrich, St. Louis, MO, USA). For immunoblotting, lysis buffer consisted of a 1:1 mixture of T-PER reagent (Pierce, Rockford, IL, USA) and 2X Tris-glycine SDS sample buffer (Novex, Life Technologies, Carlsbad, CA, USA), $33 \mathrm{mM}$ DTT, and protease and phosphatase inhibitor mixture (1X Halt mixture, Pierce). Cells were collected directly in lysis buffer and boiled for $10 \mathrm{~min}$. Cell extracts were resolved by SDS-PAGE on a 4-20\% tris-glycine gel (Invitrogen, Life Technologies). Proteins were transferred to PVDF membranes by overnight transfer as described by the manufacturer (Invitrogen, Life Technologies). Membranes were blocked with PBS $0.1 \%$ Tween $-20+3 \%$ BSA. Primary antibodies against specified proteins were incubated with the membrane in blocking solution overnight at $4^{\circ} \mathrm{C}$. Antibodies against BRCA1 (sc-642) and BRG1 (sc-10768) were purchased from Santa Cruz Biotechnology (Santa Cruz, CA, USA). The ATM (2873) antibody was purchased from Cell Signaling (Beverly, MA, USA). The $\beta$-actin antibody (ab49900) was purchased from Abcam (Boston, MA, USA). Anti-Flag (F3165) was purchased from Sigma Aldrich. Membranes were washed twice with PBS $+0.1 \%$ Tween-20 and incubated with HRP-conjugated secondary antibody for 1 hour in blocking solution. Presence of secondary antibody (\#32430 and \#32460, Pierce) was detected by SuperSignal West Dura Extended Duration Substrate (Pierce). Luminescence was visualized on a Molecular Imager ChemiDoc XRS system Bio-Rad station (Bio-Rad, Hercules, CA, USA).

\section{Small molecule compounds}

The ATM kinase inhibitor (ATMin) 2-morpholin-4-yl-6thianthren-1-yl-pyran-4-one (KU55933) and Chk2 kinase inhibitor (Chk2in) 2-(4-(4-chlorophenoxy)phenyl)-1H-benzimidazole-5-carboxamide, were purchased from EMD4 Biosciences (Gibbstown, NJ, USA). Caffeine was purchased from Sigma Aldrich. Curcumin was purchased from Santa
Cruz Biotechnology (sc-200509). All inhibitors were prepared in $10 \mathrm{mM}$ stock solution dissolved in DMSO.

\section{Transfections}

UWB1.289 and UWB1.289 + BRCA1 cells were seeded in a 96-well plate and co-transfected with $0.5 \mu \mathrm{g}$ of $p R L$-CMV-luciferase reporter (Renilla), HIV-1 LTRluciferase reporter (Firefly), and pcTat ${ }_{101}$. The Renilla reporter plasmid was co-transfected to allow correction for differences in transfection efficiency. For siRNA transfection, TZM-bl cells were co-transfected in a 96well plate with pcTat ${ }_{101}(0.5 \mu \mathrm{g})$ and siRNA against GFP (\#P-002048-01-20, Dharmacon, Lafayette, CO, USA), Hs_BRCA1_15 or Hs_ATM_5 (\#SI02664368 and \#SI00299299, Qiagen, Valencia, CA, USA), using DharmaFECT Duo (Dharmacon). For other transcriptional assays, TZM-bl cells were co-transfected in a 96-well plate with pcTat ${ }_{101}$, BRCA1 (wild-type) [73], or BRCA1 4P (S1387A/S1423A/S1457A/ S1524A) mutant [constructed by swapping a cDNA fragment harboring the S1387A and S1423A mutations into the wild-type plasmid followed by adding additional mutations with sequential rounds of QuikChange site-directed mutagenesis (Stratagene, Santa Clara, CA, USA) using primer sets: 5' GCAGTATTAACTGC ACAGAAAAGTAGTG-3' and 5' -CACTACT TTTCTGTGCAGTTAATACTGC-3' (S14 57A); 5'-GAATAGAAACTACCCAGCTCAAGAGG A$3^{\prime}$ and 5'-GAGCTCCTCTTGAGCTGGGT AGTTT CTATTC-3'(S1524A)]. All cells were collected for luminescence analysis 48 hours post-transfection, and all transfections were performed using the Attractene reagent according to the manufacturer's instructions (Qiagen) unless noted otherwise.

\section{Luciferase and viability assays}

Forty-eight hours post-transfection or drug treatment, luciferase activity of the Firefly luciferase was measured with Dual-Glo (for assays using Renilla luciferase) or Bright-Glo Luciferase Assay (Promega, Madison, WI, USA). Alternatively, CellTiter-Glo (Promega) was used to measure viability following the manufacturer's recommendations. Luminescence was read from a 96-well plate on an EG\&G Berthold luminometer (Berthold Technologies, Oak Ridge, TN, USA).

\section{GST pull-down and immunoprecipitation}

GST tagged proteins were purified as described previously [59]. Constructs were washed three times with $\mathrm{PBS}+1 \%$ Triton $\mathrm{X}-100$, pelleted and resuspended in PBS $+1 \%$ Triton $X-100$. Bead volume was normalized between samples by the addition of extra bead slurry prepared in the same manner for each condition. Whole cell protein extract from TZM-bl cells that were transfected with Flag-Tat ${ }_{101}$ for 48 hours was brought up to a 
final volume of $500 \mu \mathrm{l}$ with lysis buffer and $1 \mu \mathrm{g}$ of GST-BRCA1 constructs (1-500, 504-802, 697-1276, 1021-1552, 1501-1861) were rotated at $4^{\circ} \mathrm{C}$ overnight. GST-alone and GST-Tat beads were washed once with $\mathrm{TNE}_{150}+0.1 \% \mathrm{NP}-40$ and twice with $\mathrm{TNE}_{50}+0.1 \% \mathrm{NP}-$ 40. GST-BRCA1 beads were washed once with $\mathrm{TNE}_{300}+$ $0.1 \% \mathrm{NP}-40$, once with $\mathrm{TNE}_{150}+0.1 \% \mathrm{NP}-40$, and once with $\mathrm{TNE}_{50}+0.1 \% \mathrm{NP}-40$. For IP, $1 \mathrm{mg}$ of whole cell protein was brought up to a final volume of $500 \mu \mathrm{l}$ with $\mathrm{TNE}_{50}+0.1 \%$ NP-40 and pre-cleared for $15 \mathrm{~min}$ with $50 \mu \mathrm{l}$ of $30 \% \mathrm{~A} / \mathrm{G}$ agarose bead slurry (CalBioChem, La Jolla, CA). Supernatants were transferred to a new tube with $10 \mu \mathrm{g}$ of BRCA1 or normal rabbit IgG antibodies (Santa Cruz), and the solution was rotated overnight at $4^{\circ} \mathrm{C}$. The next day complexes were precipitated with $\mathrm{A} /$ $\mathrm{G}$ beads for $90 \mathrm{~min}$. Beads were washed once with $\mathrm{TNE}_{150}+0.1 \% \mathrm{NP}-40$ and twice with $\mathrm{TNE}_{50}+0.1 \% \mathrm{NP}-$ 40. Cells were collected directly in lysis buffer and boiled for $10 \mathrm{~min}$. The GST-construct plasmids pDC78 GST-BRCA1 (1-500), pDC80 GST-BRCA1 (10211552), pDC81 GST-BRCA1 (1501-1861), pDC99 GSTBRCA1 (504-802), pDC208 GST-BRCA1 (697-1276) were originally a kind gift from Dr. Tanya Paull at the University of Texas/ICMB [58].

\section{Reporter virus generation and infections}

$p H C M V-G$ [74], which expresses the vesicular stomatitis virus glycoprotein, and $p C M V \Delta R 8.2$ [75] have been previously described. $p N L-R R E-S A-L u c$ was generated from $p N L-L u c-R R E-S A$ [76] and $p N L-R R E-S A$ [77] by inserting the luciferase gene (Firefly) within the XhoI cloning site of $p N L-R R E-S A$. Pseudotyped virions were prepared by co-transfecting $4 \times 10^{6}$ HEK-293 T cells with $7.5 \mu \mathrm{g}$ of packaging construct $p C M V \Delta R 8.2,10 \mu \mathrm{g}$ of reporter vector plasmid $p N L-R R E-S A-L u c$, and $2.5 \mu \mathrm{g}$ of the envelope plasmid $p H C M V-G$ using Lipofectamine 2000 (Invitrogen, Life Technologies) as recommended by the manufacturer. Viral particles were harvested 2 days post-transfection, filtered through a $0.45 \mu \mathrm{m}$ nitrocellulose membrane, and stored at $-80^{\circ} \mathrm{C}$. Levels of $\mathrm{p} 24$ in the viral supernatant were measured by ELISA using an in-house ELISA kit. Twenty-four hours before infection, UWB1.289 and UWB1.289 + BRCA1 cells were seeded in a 96-well plate and co-transfected with $0.25 \mu \mathrm{g}$ of $p R L$-CMV-luciferase reporter (Renilla), and pcDNA or pcTat ${ }_{101}$. The next day, the cells were infected in $150 \mu \mathrm{L}$ of medium containing virus (p24=2,000 pg). Twenty-four hours post-infection the cells were processed for luciferase readings using the Dual-Glo system (Promega).

HIV-1 NL4-3 was generated by transfection of plasmid pNL4-3 into HEK293T cells using lipofectamine 2000 (Invitrogen) as described previously [77]. For infection, CEM T-cells were incubated with the virus (p24= $5,000 \mathrm{pg} / \mathrm{ml}$ ) for 4 hours and then washed twice with medium to remove unbound viral particles. Infected cells were resuspended in fresh RPMI supplemented with $10 \%$ heat-inactivated FBS and incubated for 72 hours prior to ChIP assays.

\section{Chromatin immunoprecipitation assays}

Cells were crosslinked with $1 \%$ paraformaldehyde for 10 min and crosslinking was stopped by the addition of $125 \mathrm{mM}$ glycine. Chromatin fragments were prepared from $5 \times 10^{6}$ cells per sample. Cells were lysed using SDS lysis buffer (1\% SDS, $10 \mathrm{mM}$ EDTA, $50 \mathrm{mM}$ Tris- $\mathrm{HCl}$ $\mathrm{pH}$ 8.0, one tablet complete protease inhibitor cocktail per $50 \mathrm{ml}$ ) on ice for $10 \mathrm{~min}$. Cells were sonicated on ice for 6 bursts of 10 seconds to obtain an average DNA length of 500 to 1000 bp (Misonix XL 2000, Misonix, NY, USA). Samples were processed as previously described [78]. Quantitative PCR was performed using SYBR Green PCR Master Mix (\#4309155, Applied Biosystems, Foster City, CA) with $5 \mu \mathrm{l}$ of immunoprecipitated material, $0.2 \mu \mathrm{M}$ of primer [HIV-1 LTR $(-69-+175)$ Forward 5'-CTGGGCGGGACTGGGGAG-3' and Reverse 5'-TCA CACAACAGACGGGCACAC-3']. The antibodies used for immunoprecipitation were as follows: total RNAP II CTD (ab817, Abcam), pS10-H3 (Novex, Life Technologies), BRCA1 (sc-642, Santa Cruz), p-BRCA1 S1423 (sc101647, Santa, Cruz), Sp1 (5931, Cell Signaling), (IgG (sc-2027, Santa Cruz) or V5 (AbD Serotec, Oxford, UK).

\section{qRT-PCR}

RNA analysis of BRCA1 and ATM transcripts was performed after selective depletion with the respective siRNA. Total RNA was isolated from cell pellets using the RNeasy Kit (Qiagen) according to the manufacturer's protocol. A total of $300 \mathrm{ng}$ of RNA was used to generate cDNA with the High-Capacity RNA-to-cDNA Kit (\#4387406, Invitrogen, Life Technologies) following manufacturer's recommendations. Quantitative PCR was performed with SYBR Green PCR Master Mix Applied Biosystems). Fold changes were calculated relative to Actin using the $\triangle \Delta \mathrm{Ct}$ method. Primers used are described: BRCA1 Forward 5'-GGCTATCCTCTCAGAGTGACA TTT-3' and $R e$ verse 5'-GCTTTATCAGGTTAT GTTGCATGGT-3' [79], ATM Forward 5' - CAGGGTAGTTTAGTTGAG GTTGACAG-3' and Reverse 5' - CTATACTGGTGGT CAGTG CCAAAGT-3' [80].

\section{Competing interests}

The authors declare that they have no competing interests.

\section{Author' contributions}

Conceived and designed the experiments: IG, KKH. Performed the experiments: IG, BWM, AB, JG, KKH. Analyzed the data: IG, KKH. Contributed reagents/materials/analysis: KV, SMD, JG, YW. Manuscript write-up: IG, KKH. All authors read and approved the final manuscript. 


\section{Acknowledgements}

We would like to thank Dr. Aarthi Narayanan (National Center for Biodefense and Infectious Diseases, George Mason University, Manassas, VA, USA) for generously providing the curcumin. We thank Dr. Fatah Kashanchi (National Center for Biodefense and Infectious Diseases, George Mason University, Manassas, VA, USA) for helpful discussions. Publication of this article was funded in part by the George Mason University Libraries Open Access Publishing Fund.

\section{Author details}

${ }^{1}$ National Center for Biodefense \& Infectious Diseases, School of Systems Biology, George Mason University, Biomedical Research Lab, 10650 Pyramid Place, MS 1J5, Manassas, VA 20110, USA. ²Department of Radiation Oncology, Virginia Commonwealth University, Richmond, VA 23298, USA. ${ }^{3}$ Department of Pharmacology and Toxicology, Virginia Commonwealth University, Richmond, VA 23298, USA.

\section{Received: 25 September 2014 Accepted: 14 February 2015}

\section{Published online: 06 March 2015}

\section{References}

1. Gatignol A. Transcription of HIV: Tat and cellular chromatin. Adv Pharmacol. 2007:55:137-59.

2. $\quad$ Peng J, Zhu Y, Milton JT, Price DH. Identification of multiple cyclin subunits of human P-TEFb. Genes Dev. 1998;12:755-62.

3. Fujinaga K, Cujec TP, Peng J, Garriga J, Price DH, Grana X, et al. The ability of positive transcription elongation factor $B$ to transactivate human immunodeficiency virus transcription depends on a functional kinase domain, cyclin T1, and Tat. J Virol. 1998;72:7154-9.

4. Herrmann $\mathrm{CH}$, Rice AP. Lentivirus Tat proteins specifically associate with a cellular protein kinase, TAK, that hyperphosphorylates the carboxyl-terminal domain of the large subunit of RNA polymerase II: candidate for a Tat cofactor. J Virol. 1995:69:1612-20.

5. Laspia MF, Rice AP, Mathews MB. HIV-1 Tat protein increases transcriptional initiation and stabilizes elongation. Cell. 1989;59:283-92.

6. Nabel G, Baltimore D. An inducible transcription factor activates expression of human immunodeficiency virus in T cells. Nature. 1987;326:711-3.

7. Sobhian B, Laguette N, Yatim A, Nakamura M, Levy Y, Kiernan R, et al. HIV-1 Tat assembles a multifunctional transcription elongation complex and stably associates with the 7SK snRNP. Mol Cell. 2010;38:439-51.

8. Garber ME, Wei P, Jones KA. HIV-1 Tat interacts with cyclin T1 to direct the P-TEFb CTD kinase complex to TAR RNA. Cold Spring Harb Symp Quant Biol. 1998:63:371-80.

9. Wei P, Garber ME, Fang SM, Fischer WH, Jones KA. A novel CDK9-associated C-type cyclin interacts directly with HIV-1 Tat and mediates its high-affinity, loop-specific binding to TAR RNA. Cell. 1998;92:451-62.

10. Zhou M, Deng L, Lacoste V, Park HU, Pumfery A, Kashanchi F, et al. Coordination of transcription factor phosphorylation and histone methylation by the P-TEFb kinase during human immunodeficiency virus type 1 transcription. J Virol. 2004;78:13522-33.

11. Andersen JL, Zimmerman ES, DeHart JL, Murala S, Ardon O, Blackett J, et al ATR and GADD45alpha mediate HIV-1 Vpr-induced apoptosis. Cell Death Differ. 2005;12:326-34.

12. Coberley CR, Kohler JJ, Brown JN, Oshier JT, Baker HV, Popp MP, et al. Impact on genetic networks in human macrophages by a CCR5 strain of human immunodeficiency virus type 1. J Virol. 2004;78:11477-86.

13. Zimmerman ES, Chen J, Andersen JL, Ardon O, Dehart JL, Blackett J, et al. Human immunodeficiency virus type 1 Vpr-mediated G2 arrest requires Rad17 and Hus 1 and induces nuclear BRCA1 and gamma-H2AX focus formation. Mol Cell Biol. 2004;24:9286-94.

14. Yang YX, Guen V, Richard J, Cohen EA, Berthoux L. Cell context-dependent involvement of ATR in early stages of retroviral replication. Virology. 2010;396:272-9.

15. Dimitrov SD, Lu D, Naetar N, Hu Y, Pathania S, Kanellopoulou C, et al. Physiological modulation of endogenous BRCA1 p220 abundance suppresses DNA damage during the cell cycle. Genes Dev. 2013;27:2274-91.

16. De Siervi A, De Luca P, Byun JS, Di LJ, Fufa T, Haggerty CM, et al. Transcriptional autoregulation by BRCA1. Cancer Res. 2010;70:532-42.

17. Monteiro AN, August A, Hanafusa H. Evidence for a transcriptional activation function of BRCA1 C-terminal region. Proc Natl Acad Sci U S A. 1996;93:13595-9.
18. Glover JN, Williams RS, Lee MS. Interactions between BRCT repeats and phosphoproteins: tangled up in two. Trends Biochem Sci. 2004;29:579-85.

19. Scully R, Anderson SF, Chao DM, Wei W, Ye L, Young RA, et al. BRCA1 is a component of the RNA polymerase II holoenzyme. Proc Natl Acad Sci U S A. 1997:94:5605-10.

20. Krum SA, Miranda GA, Lin C, Lane TF. BRCA1 associates with processive RNA polymerase II. J Biol Chem. 2003;278:52012-20.

21. Anderson SF, Schlegel BP, Nakajima T, Wolpin ES, Parvin JD. BRCA1 protein is linked to the RNA polymerase II holoenzyme complex via RNA helicase A. Nat Genet. 1998;19:254-6.

22. Pao GM, Janknecht $R$, Ruffner $H$, Hunter T, Verma IM. CBP/p300 interact with and function as transcriptional coactivators of BRCA1. Proc Natl Acad Sci U S A. 2000;97:1020-5.

23. Rosen EM, Fan S, Pestell RG, Goldberg ID. BRCA1 gene in breast cancer. J Cell Physiol. 2003;196:19-41.

24. Harkin DP, Bean JM, Miklos D, Song YH, Truong VB, Englert C, et al. Induction of GADD45 and JNK/SAPK-dependent apoptosis following inducible expression of BRCA1. Cell. 1999;97:575-86.

25. Jin S, Zhao H, Fan F, Blanck P, Fan W, Colchagie AB, et al. BRCA1 activation of the GADD45 promoter. Oncogene. 2000;19:4050-7.

26. Ouchi T, Monteiro AN, August A, Aaronson SA, Hanafusa H. BRCA1 regulates p53-dependent gene expression. Proc Natl Acad Sci U S A. 1998;95:2302-6.

27. Somasundaram K. Breast cancer gene 1 (BRCA1): role in cell cycle regulation and DNA repair-perhaps through transcription. J Cell Biochem. 2003:88:1084-91.

28. Somasundaram $K$, Zhang $H$, Zeng $Y X$, Houvras $Y$, Peng $Y$, Zhang $H$, et al. Arrest of the cell cycle by the tumour-suppressor BRCA1 requires the CDKinhibitor p21WAF1/CiP1. Nature. 1997:389:187-90.

29. Williamson EA, Dadmanesh F, Koeffler HP. BRCA1 transactivates the cyclindependent kinase inhibitor p27(Kip1). Oncogene. 2002;21:3199-206.

30. Zhang $H$, Somasundaram $K$, Peng $Y$, Tian H, Zhang H, Bi D, et al. BRCA1 physically associates with p53 and stimulates its transcriptional activity. Oncogene. 1998;16:1713-21.

31. Cabart P, Chew HK, Murphy S. BRCA1 cooperates with NUFIP and P-TEFb to activate transcription by RNA polymerase II. Oncogene. 2004;23:5316-29.

32. Bochar DA, Wang L, Beniya $H$, Kinev $A$, Xue $Y$, Lane WS, et al. BRCA1 is associated with a human SWI/SNF-related complex: linking chromatin remodeling to breast cancer. Cell. 2000;102:257-65.

33. Harte MT, O'Brien GJ, Ryan NM, Gorski JJ, Savage Kl, Crawford NT, et al. BRD7, a subunit of SWI/SNF complexes, binds directly to BRCA1 and regulates BRCA1-dependent transcription. Cancer Res. 2010;70:2538-47.

34. Xu Y, Sun Y, Jiang X, Ayrapetov MK, Moskwa P, Yang S, et al. The p400 ATPase regulates nucleosome stability and chromatin ubiquitination during DNA repair. J Cell Biol. 2010;191:31-43

35. Zhang $L$, Chen $H$, Gong M, Gong F. The chromatin remodeling protein BRG1 modulates BRCA1 response to UV irradiation by regulating ATR/ATM activation. Front Oncol. 2013:3:7.

36. Tu Z, Aird KM, Zhang R. Chromatin remodeling, BRCA1, SAHF and cellular senescence. Cell Cycle. 2013;12:1653-4.

37. Miki Y, Swensen J, Shattuck-Eidens D, Futreal PA, Harshman K, Tavtigian S, et al. A strong candidate for the breast and ovarian cancer susceptibility gene BRCA1. Science. 1994;266:66-71.

38. Kawai $\mathrm{S}$, Amano A. BRCA1 regulates microRNA biogenesis via the DROSHA microprocessor complex. J Cell Biol. 2012;197:201-8.

39. Yarden RI, Brody LC. BRCA1 interacts with components of the histone deacetylase complex. Proc Natl Acad Sci U S A. 1999;96:4983-8.

40. DelloRusso C, Welcsh PL, Wang W, Garcia RL, King MC, Swisher EM. Functional characterization of a novel BRCA1-null ovarian cancer cell line in response to ionizing radiation. Mol Cancer Res. 2007;5:35-45.

41. Romani B, Engelbrecht S, Glashoff RH. Functions of Tat: the versatile protein of human immunodeficiency virus type 1. J Gen Virol. 2010;91:1-12.

42. Frankel $A D$, Bredt DS, Pabo CO. Tat protein from human immunodeficiency virus forms a metal-linked dimer. Science. 1988;240:70-3.

43. Huen MS, Sy SM, Chen J. BRCA1 and its toolbox for the maintenance of genome integrity. Nat Rev Mol Cell Biol. 2010;11:138-48.

44. Kashanchi F, Agbottah ET, Pise-Masison CA, Mahieux R, Duvall J, Kumar A, et al. Cell cycle-regulated transcription by the human immunodeficiency virus type 1 Tat transactivator. J Virol. 2000;74:652-60.

45. Ogiwara H, Ui A, Shiotani B, Zou L, Yasui A, Kohno T. Curcumin suppresses multiple DNA damage response pathways and has potency as a sensitizer to PARP inhibitor. Carcinogenesis. 2013;34:2486-97. 
46. Ji Z. Targeting DNA damage and repair by curcumin. Breast Cancer : Basic and Clin Res. 2010;4:1-3.

47. Narayanan A, Kehn-Hall K, Senina S, Lundberg L, Van Duyne R, Guendel I, et al. Curcumin inhibits Rift Valley fever virus replication in human cells. J Biol Chem. 2012;287:33198-214.

48. Bansal Y, Silakari O. Multifunctional compounds: Smart molecules for multifactorial diseases. Eur J Med Chem. 2014;76C:31-42.

49. Bhullar KS, Jha A, Youssef D, Rupasinghe HP. Curcumin and its carbocyclic analogs: structure-activity in relation to antioxidant and selected biological properties. Molecules. 2013;18:5389-404.

50. Rowe DL, Ozbay T, O'Regan RM, Nahta R. Modulation of the BRCA1 Protein and Induction of Apoptosis in Triple Negative Breast Cancer Cell Lines by the Polyphenolic Compound Curcumin. Breast Cancer : Basic and Clin Res. 2009:3:61-75.

51. Gandapu U, Chaitanya RK, Kishore G, Reddy RC, Kondapi AK. Curcuminloaded apotransferrin nanoparticles provide efficient cellular uptake and effectively inhibit HIV-1 replication in vitro. PLoS One. 2011;6:e23388.

52. Guo L, Xing Y, Pan R, Jiang M, Gong Z, Lin L, et al. Curcumin protects microglia and primary rat cortical neurons against HIV-1 gp120-mediated inflammation and apoptosis. PLoS One. 2013;8:e70565.

53. Tang H, Lu D, Pan R, Qin X, Xiong H, Dong J. Curcumin improves spatial memory impairment induced by human immunodeficiency virus type 1 glycoprotein 120 V3 loop peptide in rats. Life Sci. 2009:85:1-10.

54. Riva DA, Fernandez-Larrosa PN, Dolcini GL, Martinez-Peralta LA, Coulombie FC, Mersich SE. Two immunomodulators, curcumin and sulfasalazine enhance IDV antiretroviral activity in HIV-1 persistently infected cells. Arch Virol. 2008;153:561-5.

55. Zhang HS, Ruan Z, Sang WW. HDAC1/NFkappaB pathway is involved in curcumin inhibiting of Tat-mediated long terminal repeat transactivation. J Cell Physiol. 2011;226:3385-91.

56. Traven A, Heierhorst J. SQ/TQ cluster domains: concentrated ATM/ATR kinase phosphorylation site regions in DNA-damage-response proteins. Bioessays. 2005;27:397-407

57. Tibbetts RS, Cortez D, Brumbaugh KM, Scully R, Livingston D, Elledge SJ, et al. Functional interactions between BRCA1 and the checkpoint kinase ATR during genotoxic stress. Genes Dev. 2000;14:2989-3002.

58. Cortez D, Wang Y, Qin J, Elledge SJ. Requirement of ATM-dependent phosphorylation of brca1 in the DNA damage response to double-strand breaks. Science. 1999;286:1162-6.

59. Gatei M, Scott SP, Filippovitch I, Soronika N, Lavin MF, Weber B, et al. Role for ATM in DNA damage-induced phosphorylation of BRCA1. Cancer Res. 2000;60:3299-304.

60. Lee JS, Collins KM, Brown AL, Lee $\mathrm{CH}$, Chung JH. hCds1-mediated phosphorylation of BRCA1 regulates the DNA damage response. Nature. 2000:404:201-4.

61. Valerie K, Delers A, Bruck C, Thiriart C, Rosenberg H, Debouck C, et al. Activation of human immunodeficiency virus type 1 by DNA damage in human cells. Nature. 1988:333:78-81.

62. Zhou BB, Chaturvedi P, Spring K, Scott SP, Johanson RA, Mishra R, et al. Caffeine abolishes the mammalian G(2)/M DNA damage checkpoint by inhibiting ataxia-telangiectasia-mutated kinase activity. J Biol Chem. 2000;275:10342-8.

63. Hickson I, Zhao Y, Richardson CJ, Green SJ, Martin NM, Orr Al, et al. Identification and characterization of a novel and specific inhibitor of the ataxia-telangiectasia mutated kinase ATM. Cancer Res. 2004;64:9152-9.

64. Zhang J, Willers H, Feng Z, Ghosh JC, Kim S, Weaver DT, et al. Chk2 phosphorylation of BRCA1 regulates DNA double-strand break repair. Mol Cell Biol. 2004;24:708-18.

65. Nunnari G, Argyris E, Fang J, Mehlman KE, Pomerantz RJ, Daniel R. Inhibition of HIV-1 replication by caffeine and caffeine-related methylxanthines. Virology. 2005;335:177-84.

66. Ariumi Y, Turelli P, Masutani M, Trono D. DNA damage sensors ATM, ATR DNA-PKCs, and PARP-1 are dispensable for human immunodeficiency virus type 1 integration. J Virol. 2005;79:2973-8.

67. Lau A, Swinbank KM, Ahmed PS, Taylor DL, Jackson SP, Smith GC, et al. Suppression of HIV-1 infection by a small molecule inhibitor of the ATM kinase. Nat Cell Biol. 2005;7:493-500.

68. Koyama T, Sun B, Tokunaga K, Tatsumi M, Ishizaka Y. DNA damage enhances integration of HIV-1 into macrophages by overcoming integrase inhibition. Retrovirology. 2013;10:21.
69. Napolitano G, Amente S, Castiglia V, Gargano B, Ruda V, Darzacq X, et al. Caffeine prevents transcription inhibition and P-TEFb/7SK dissociation following UV-induced DNA damage. PLoS One. 2010;5:e11245.

70. Derdeyn CA, Decker JM, Sfakianos JN, Wu X, O'Brien WA, Ratner L, et al. Sensitivity of human immunodeficiency virus type 1 to the fusion inhibitor T-20 is modulated by coreceptor specificity defined by the V3 loop of gp120. J Virol. 2000;74:8358-67.

71. Wei X, Decker JM, Liu H, Zhang Z, Arani RB, Kilby JM, et al. Emergence of resistant human immunodeficiency virus type 1 in patients receiving fusion inhibitor (T-20) monotherapy. Antimicrob Agents Chemother. 2002;46:1896-905.

72. Scully R, Ganesan S, Vlasakova K, Chen J, Socolovsky M, Livingston DM. Genetic analysis of BRCA1 function in a defined tumor cell line. Mol Cell. 1999:4:1093-9.

73. Dever SM, Golding SE, Rosenberg E, Adams BR, Idowu MO, Quillin JM, et al Mutations in the BRCT binding site of BRCA1 result in hyper-recombination. Aging. 2011;3:515-32.

74. Yee JK, Miyanohara A, LaPorte P, Bouic K, Burns JC, Friedmann T. A general method for the generation of high-titer, pantropic retroviral vectors: highly efficient infection of primary hepatocytes. Proc Natl Acad Sci U S A. 1994;91:9564-8.

75. Naldini L, Blomer U, Gallay P, Ory D, Mulligan R, Gage FH, et al. In vivo gene delivery and stable transduction of nondividing cells by a lentiviral vector. Science. 1996;272:263-7.

76. Wang Z, Tang Z, Zheng Y, Yu D, Spear M, lyer SR, et al. Development of a nonintegrating Rev-dependent lentiviral vector carrying diphtheria toxin A chain and human TRAF6 to target HIV reservoirs. Gene Ther. 2010;17:1063-76.

77. Young J, Tang Z, Yu Q, Yu D, Wu Y. Selective killing of HIV-1-positive macrophages and T cells by the Rev-dependent lentivirus carrying anthrolysin $\mathrm{O}$ from Bacillus anthracis. Retrovirology. 2008;5:36.

78. Guendel I, Carpio L, Pedati C, Schwartz A, Teal C, Kashanchi F, et al. Methylation of the tumor suppressor protein, BRCA1, influences its transcriptional cofactor function. PLoS One. 2010;5:e11379.

79. Taron M, Rosell R, Felip E, Mendez P, Souglakos J, Ronco MS, et al. BRCA1 mRNA expression levels as an indicator of chemoresistance in lung cancer. Hum Mol Genet. 2004;13:2443-9.

80. Ai L, Skehan RR, Saydi J, Lin T, Brown KD. Ataxia-Telangiectasia, Mutated (ATM)/Nuclear Factor kappa light chain enhancer of activated B cells (NFkappaB) signaling controls basal and DNA damage-induced transglutaminase 2 expression. J Biol Chem. 2012;287:18330-41.

\section{Submit your next manuscript to BioMed Central and take full advantage of:}

- Convenient online submission

- Thorough peer review

- No space constraints or color figure charges

- Immediate publication on acceptance

- Inclusion in PubMed, CAS, Scopus and Google Scholar

- Research which is freely available for redistribution 